Revista de Antropología Social

ISSN: 1131-558X

http://dx.doi.org/10.5209/RASO.59439

\title{
La ciudad, línea abismal. Identidades de clase en Bangkok
}

Vorng, Sophorntavy. 2017. A Meeting of Masks: Status, Power and Hierarchy in Bangkok. Copenhague: NIAS Press.

Cuando la antropología mira hacia Asia, y en particular hacia sus ciudades, pareciera como si estuviera obligada a hacer un deliberado ejercicio de equilibrio para no caer, por un lado, en el excepcionalismo orientalista pero sin hacerlo tampoco en el globalismo eurocéntrico. Sin embargo, la obra que aquí se reseña no busca sortear estas perspectivas esencialistas, sino que dialoga con ellas para dar una respuesta que las supere yendo a la misma base del hecho social.

Este trabajo continúa lo propuesto en otros proyectos de Sophorntavy Vorng (investigadora del Instituto Max Planck de Göttingen) centrados en el status, las creencias, las adicciones y el consumo en Tailandia. En este caso se sitúa en Bangkok, centro de las tensiones políticas del país en la última década, para desarrollar su ambicioso objetivo de investigación: comprender el funcionamiento del sistema social urbano y sus jerarquías, y cómo en estas están contenidas la identidad de los sujetos, sus discursos y prácticas. Las transformaciones del lenguaje, los imaginarios del espacio, la presentación corporal, la diversidad étnica, etc., son las piezas a partir de las cuales Vorng da forma a un material etnográfico de gran volumen, recopilado en dos etapas: dieciocho meses de trabajo de campo (entre 2005 y 2007) acompañado de trabajo de seguimiento en posteriores años, hasta enero de 2011. Las técnicas empleadas son la observación participante en distintos espacios - bodas, funerales, graduaciones, centros comerciales - , los grupos de discusión y, principalmente, las entrevistas personales realizadas a "más de cien informantes" (p. 17), como se señala con notable ambigüedad. El análisis de los datos revela la adscripción a un marco unívocamente emic para dibujar un objeto de estudio de orden inter-subjetivo: las identificaciones de clase y status de los ciudadanos de Bangkok. Sin embargo, el reconocimiento explícito del sesgo muestral, sobrerrepresentado por aquellos informantes que, en palabras de la autora "eran capaces de articularse a sí mismos mejor en las entrevistas" [p. 18] (es decir, individuos formados que en su mayoría habían estudiado en el extranjero), da cuenta de las limitaciones de este tipo de enfoque. Pero, a la vez, descubre lo que considero el espíritu implícito de la investigación: elaborar una antropología de la clase media urbana, concebida esta última como una categoría problemática pero necesaria para comprender las identidades en las ciudades del sudeste asiático.

La estructura de la obra es de lógica descendente, de lo estructural a lo concreto. En una primera introducción, se sumerge al lector en el contexto político de Tailandia a través de un breve recorrido por la historia contemporánea del país, marcada por conflictos que han superado su naturaleza inter-elitista original para instalarse en la realidad cotidiana de los ciudadanos. La intensificación en la última década de las protestas en las calles, así como de la represión, la violencia y la polarización 
social — los "amarillos", clases medias urbanas; los "rojos", inmigrantes ruralesmuestra hasta qué punto el conflicto institucional ha derivado en un conflicto social de orden clasista y étnico. En este sentido se entiende la recurrente mención de la quema por parte de los manifestantes del Central World Plaza, un centro comercial en Bangkok, en mayo de 2011. Para entonces, Vorng ya había finalizado su trabajo de campo — al calor de la ola de protestas de esos años - y, en el análisis, dota al suceso de un sentido metonímico, como representación de la ira popular contra las jerarquías sociales de la ciudad.

Entrando en el contenido central de la obra, conviene advertir que los dos primeros capítulos están reservados al marco teórico e histórico, donde la autora realiza un ejercicio minucioso de traducción cultural: en primer lugar, describe el sistema de castas tailandés, o sakdina, su evolución histórica y de qué formas se reactiva en la vida social urbana; en segundo lugar, explica cómo está socialmente construido $-\mathrm{y}$ distribuido - el espacio en Bangkok, detallando las diferentes realidades que entran en juego como la cosmología budista, las relaciones coloniales o los sistemas morales tradicionales y sus normas de comportamiento vinculadas al lugar. Una caracterización histórica y cultural del problema que el lector foráneo agradecerá, apoyada por la presencia de varios mapas, además de un glosario de categorías analíticas y términos en tailandés que la autora no rehúsa utilizar en numerosas ocasiones.

Los tres siguientes capítulos son de contenido estrictamente etnográfico, momento en el que a la voz de la autora se añade la de sus informantes. En sus discursos, dominados por los lenguajes de competitividad y distinción, Vorng rastrea la conformación de la subjetividad desde el status y, escapando de nociones deterministas, analiza las tensiones internas del sujeto en la composición de su identidad de "clase media", expresadas en la ansiedad y en las ocasionales resistencias frente a la recia jerarquización de la sociedad. Por esta razón, el mall o centro comercial es el lugar elegido recurrentemente para esta inquisición, en tanto que representa de forma idónea esa heterotopía, la de un espacio constituido para el fetichismo por la mercancía global - y por sus centros de consumo - que en Bangkok marca las lógicas de inclusión/exclusión en la modernidad, en este caso desde una cultura del mall abiertamente segregacionista. Un imaginario donde lo urbano es presentado como un estilo de vida que es un valor en sí mismo que el sujeto debe apropiarse, insertándolo en su existencia y, sobre todo, en su apariencia; y, simultáneamente, donde lo rural es depreciado y reificado, así como los grupos étnicos asociados a ese mundo. Y es que una de las principales aportaciones de A Meeting of Masks: Status, Power and Hierarchy in Bangkok es la exposición de la particularidad que toma la colonialidad estética en una ciudad como Bangkok, donde la influencia y poder de la minoría chino-tailandesa cohabita con la "americanización" de los objetos sociales de distinción. Los patrones raciales y étnicos nativos son estereotipados, concebidos por los sujetos como limitaciones, atrasos; lo foráneo, al contrario, es mistificado como símbolo de desarrollo proveniente de China, Estados Unidos y Europa. Por este motivo, quizá se echa en falta una descripción de las características étnicas de cada informante citado para poder contextualizar su discurso. Aun así, la gran variedad de fuentes de obtención de datos etnográficos prueban la transversalidad y hegemonía de estos imaginarios.

La obra consigue comprender el fenómeno de la globalización — tan problemático en la literatura académica - en su realización local y concreta. Funcionaría, de esta manera, como una suerte de guía en la que Vorng da pistas para estudios alterna- 
tivos de lo urbano desde dos ejes principales. Por un lado, la operacionalización emic de la categoría "clase media" oculta las desigualdades materiales - he ahí donde son más notables los inconvenientes de su uso- a la vez que funciona eficazmente para entender un tipo de subjetividad compartida y propia de la modernidad, vinculada al status, que integra elementos de los sistemas jerárquicos nativos. Por otro lado, la problematización de la dicotomía rural-urbano, uno de los objetivos explícitos de la investigación, se apoya en una esclarecedora genealogía del espacio social en Tailandia que nos aleja de las clásicas miradas eurocéntricas hacia las grandes ciudades asiáticas como una transposición caótica de algo originariamente occidental, y permite pensar la especificidad local de Bangkok como una variación única en el polifónico paisaje de las ciudades globalizadas. Así, la autora bascula de forma sugerente entre una antropología "en" la ciudad y "de" la ciudad, y nos advierte, con sus aciertos y errores, de los límites y posibilidades de este tipo de aproximaciones.

José Barrera Blanco Universidad Complutense de Madrid josbar01@ucm.es 